\title{
RISK-BASED SECURITY ASSESSMENT OF POWER SYSTEM VOLTAGE DROP: A CASE STUDY OF NIGERIAN 330KV 41-BUS TRANSMISSION GRID
}

\author{
U. N. Asibeluo ${ }^{1, *}$ and T. C. Madueme ${ }^{2}$

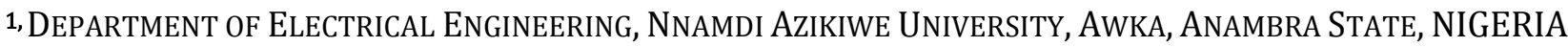 \\ 2, DEPARTMENT OF ELECTRICAL ENGINEERING, UNIVERSITY OF NigERIA, NSUKKA, ENUGU STATE, NIGERIA \\ E-mail addresses: ${ }^{1}$ uzuazokaro397@gmail.com, 2 theophilus.madueme@unn.edu.ng
}

\begin{abstract}
Researchers, system operators, engineers, and utility owners are making extensive efforts to fully utilize the installed facilities of power systems in response to increasing energy demand and thereby creating security challenges for power systems. Thus, this paper addresses the problem of power system security using the risk-based security assessment. A linearized risk-based method which uses fast decoupled load flow algorithm was used to assess the low voltage security of power systems. The method is based on the concept of risk, which considers both the likelihood of occurrence and the severity of the contingency. It requires the probability of voltage distribution, the probability of contingency and severity function to evaluate the impact of the contingency. The proposed method was illustrated on a real power system, the simulation model of the Nigerian 41 bus $330 \mathrm{kV}$ transmission grid network for calculating the risk indices of three simulated contingencies at various rates of occurrence. The calculated risk indices show that as the rate of occurrence increases, risk indices increase. This indicates that contingencies with high rate of occurrence with little impact possess higher or equivalent risk to contingencies with great impact, which rarely occur. Therefore, system operator, technician, and engineer should quickly identify, investigate, and proffer solution to them in order to alleviate their effects on the network and improve service delivery.
\end{abstract}

Keywords: Contingency, risk-based index, severity function, power system security

\section{INTRODUCTION}

The growing population and urbanization of Nigeria have resulted to the increase in size and complexity of the Nigeria power system network. Most components of the network are interconnected into a vast power grid for economic and technological reasons [1]. A response to increased power demand up to 19,100MW compared to the network operational capability of $5,500 \mathrm{MW}[2]$ is to fully utilize the installed facilities of the power system. However, power systems operated at this state are closer to their thermal and stability limits and they are constantly subjected to contingencies [3]. In order to limit the consequences of contingencies that are unpredictable and unavoidable in power systems, power systems security assessment must be carried out. Power system security involves practices, designed to keep the system operating even if one or more components fails [4].Determination of power system security level is done by two methods: deterministic and probabilistic (Risk-Based) methods. Deterministic methods evaluate security levels based on the most severe and credible contingency while probabilistic methods are based on the concept of risk which considers both probability and impact of the contingency $[5,6,7,8]$.

This paper is aimed at evaluating the Nigerian 330KV transmission grid using the Risk-Based security assessment (RBSA) approach.

\section{CONCEPT OF RISK}

Risk is defined as a condition under which there is a possibility of an adverse deviation from a desired outcome that is expected or hoped for [9]. The risk of a power system is referred to as the system's exposure to failure and its analysis is done by considering both the probability of occurrence of an event and the impact of the event [10]. Furthermore, the amount of impact multiplied by the corresponding probability of outcome is refers to as the "degree of risk" [9]. The degree of risk of the current operating condition can be quantified as "risk index" [11]. 
The risk index can quantitatively capture probabilities (likelihood) of occurrence of contingencies and their impact. In simplified terms, risk index is the product of event likelihood and its severity.

In mathematical terms;

Risk Index

$=$ (probability of event occurring)

$\times$ (Impact of event occurring)

From equation (1), the risk index of a real power system will be[10];

$$
\begin{aligned}
\operatorname{Risk}\left(S M_{t, f}\right)= & \sum_{i} P_{r}\left(E_{i}\right)\left[\sum_{i} P_{r}\left(S M \mid E_{i}, X_{t, f}\right)\right. \\
& \left.\times \operatorname{Sev}\left(E_{i}, S M\right)\right]
\end{aligned}
$$

Where,

$X_{t, f}$ : is forecast uncertain loading condition at time t.

$\mathrm{P}_{\mathrm{r}}\left(\mathrm{SM} \mid \mathrm{E}_{\mathrm{i}}, X_{t, f}\right)$ : Probability of the stability margin for $\mathrm{i}^{\text {th }}$ contingency and forecast uncertain loading condition.

$\mathrm{P}_{\mathrm{r}}\left(\mathrm{E}_{\mathrm{i}}\right)$ : Probability of $\mathrm{i}^{\text {th }}$ contingency

Sev $\left(E_{i}, S M\right)$ : Severity function which quantify the impact of the $i^{\text {th }}$ contingency with variation of stability margin. Equation (2) can be written in integral form as [10];

$$
\begin{aligned}
\operatorname{Risk}\left(S M_{t, f}\right)= & \sum_{i} P_{r}\left(E_{i}\right)\left[\int_{-\infty}^{\infty} P_{r}\left(S M \mid E_{i}, X_{t, f}\right)\right. \\
& \left.\times \operatorname{Sev}\left(E_{i}, S M\right) d S M\right]
\end{aligned}
$$

\section{THE LINEAR APPROXIMATION METHOD}

Sensitivity based method of probabilistic contingency analysis was adopted to evaluate the linear approximation method because sensitivity techniques are quick and easy ways of computing any possible violations of operating limits. The linear approximation method requires the probability of voltage distribution, probability of contingency, and the severity function to evaluate the severity of the contingency.

\subsection{Probability of Voltage Distribution}

The probability of voltage distribution requires the standard deviation calculation from variance covariance matrix (Cp) and the sensitivities of voltage with respect to active power (P) and reactive power (Q). These sensitivities are developed from the Jacobian matrix (J) of the basic load flow algorithm by simply inverting the Jacobian matrix. Equation (4) shows the Jacobian matrix (J) of Fast Decoupled Power Flow [12].

$$
J=\left[\begin{array}{cccccc}
\frac{\partial P_{2}}{\partial \delta_{2}} & \cdots & \frac{\partial P_{2}}{\partial \delta_{n}} & & & \\
\vdots & \ddots & \vdots & & 0 & \\
\frac{\partial P_{n}}{\partial \delta_{2}} & \cdots & \frac{\partial P_{n}}{\partial \delta_{n}} & & & \\
& & & \frac{\partial Q_{2}}{\partial\left|V_{2}\right|} & \cdots & \frac{\partial Q_{2}}{\partial\left|V_{n}\right|} \\
& & & \vdots & \ddots & \vdots \\
& 0 & & \frac{\partial Q_{n}}{\partial\left|V_{2}\right|} & \cdots & \frac{\partial Q_{n}}{\partial\left|V_{n}\right|}
\end{array}\right]
$$

The sensitivities of only stressed buses voltage with respect to load bus active power and reactive power are evaluated for the low voltage risk assessment. The sensitivities of the voltages are located at the particular row of $J^{-1}$. Hence, we evaluate that particular row for the stressed buses.

After screening all the buses, the stressed voltage buses are identified and their particular row in the Jacobian matrix is inverted. Assume that the stressed voltage bus is $i^{\text {th }}$ bus, the sensitivity vector (Sp) for the probability calculation will be;

$$
\left[S_{p}\right]=\left[\begin{array}{c}
\frac{\delta V_{i}}{\delta Q_{2}} \\
\vdots \\
\delta V_{i} \\
\delta Q_{n}
\end{array}\right]
$$

The variance - covariance matrix $\left(\mathrm{C}_{\mathrm{p}}\right)$ can be obtained from historical data for real control room calculations. It is assumed that non - diagonal elements are zero as there is no dependence between loads on different buses and the diagonal elements are square of the product of the load and load standard deviation. The variance - covariance matrix is given as;

$$
\left[C_{p}\right]=\left[\begin{array}{ccc}
\sigma Q_{1}{ }^{2} & \cdots & 0 \\
\vdots & \ddots & \vdots \\
0 & \cdots & \sigma Q_{n l}{ }^{2}
\end{array}\right]
$$

The sensitivity of $\mathrm{V}_{\mathrm{i}}$ and the variance - covariance matrix $\left(\mathrm{C}_{\mathrm{p}}\right)$ of the uncertain operating parameters are required to evaluate the variance of $V_{i}$. The variance of $\mathrm{V}_{\mathrm{i}}$ will be;

$$
\begin{aligned}
\gamma V_{i}=\left[\begin{array}{lll}
\frac{\partial V_{i}}{\partial Q_{i}} & \cdots \cdots & \frac{\partial V_{i}}{\partial Q_{n}}
\end{array}\right] \\
\times\left[\begin{array}{ccc}
\sigma Q_{1}{ }^{2} & \cdots & 0 \\
\vdots & \ddots & \vdots \\
0 & \cdots & \sigma Q_{n l}{ }^{2}
\end{array}\right]\left[\begin{array}{c}
\frac{\partial V_{i}}{\partial Q_{i}} \\
\vdots \\
\frac{\partial V_{i}}{\partial Q_{n}}
\end{array}\right]
\end{aligned}
$$

Hence the standard deviation $\sigma$ will be;

$$
\sigma V_{i}=\sqrt{\gamma V_{i}}
$$

$V_{i}$ is assumed to be normally distributed and therefore, the probability distribution of $V_{i}$ is

$$
P_{r}\left(V_{i}\right)=\frac{1}{\sigma V_{i} \sqrt{2 \pi}} e^{\frac{-\left(V_{i}-\mu V_{i}\right)^{2}}{2 \sigma^{2} V_{i}}}
$$


Where: $P_{r}\left(V_{i}\right)$ is the probability distribution of $V_{i}, \sigma V_{i}$ is the standard deviation of $V_{i}$, and $\mu V_{i}$ is the mean deviation of $V_{i}$

\subsection{Probability of Contingency}

The events of contingency $\left(E_{i}\right)$ are modeled to be Poisson distributed since they are rare events. The probability of a certain contingency is the probability that the contingency occurs at least one time in next hour [10].

$P_{r} E_{i}=\sum_{x=1}^{\infty} P_{r}(x)=1-P_{r}(x=0)=1-e^{-\lambda_{i}}$

Where: $\lambda_{i}$ is the occurrence rate of contingency per time interval and $E_{i}$ is the $i^{t h}$ contingency.

The occurrence rate of the contingency for a year can be obtained from the historical data and occurrence rate for an hour is by dividing the yearly rate by 8760 .

\subsection{Low Voltage Severity Function}

Severity function $(\operatorname{Sev}(\mathrm{x}))$ is introduced to quantitatively evaluate the severity of the network condition in terms of performance indicator $[6,13]$. Continuous severity function is selected because it measures the extent of the violation and it can be easily composed. The severity of the contingencies is measured in terms of voltage drop. It evaluates to 1.0 for each bus at the deterministic limits (0.95 p.u.) and increases linearly as voltage magnitude fall below limits as illustrated in Figure 1

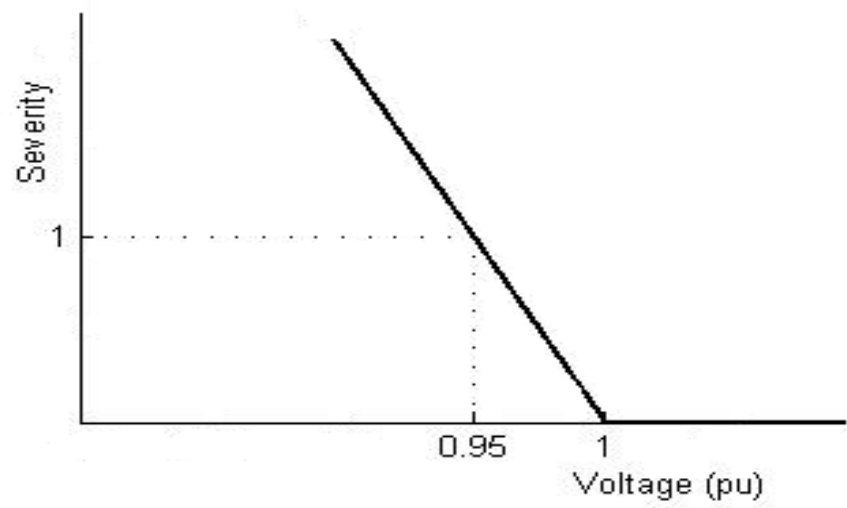

Figure 1: Continuous severity functions for low voltage [13].

\subsection{Risk Evaluation}

In order to evaluate the risk of low voltage, equation

(2) is modified as follows [10]:

$$
\begin{aligned}
\operatorname{Risk}\left(X_{t, f}\right)=\sum_{i} & P_{r}\left(E_{i}\right) \sum_{i}\left[\int_{-\infty}^{\infty} P_{r}\left(V_{i} / E_{i} X_{t, f}\right)\right. \\
& \left.\times \operatorname{Sev}\left(E_{i} V_{i}\right) d V_{i}\right]
\end{aligned}
$$

Where: $\mathrm{X}_{\mathrm{t}, \mathrm{f}}$ is forecast uncertain loading conditions at time t. $P_{r}\left(V_{i} / E_{i} X_{t, f}\right)$ : is the probability of the stressed voltage of $\mathrm{i}^{\text {th }}$ bus for $\mathrm{i}^{\text {th }}$ contingency and forecast uncertain loading condition., $P_{r}\left(E_{i}\right)$ : is the probability of $\mathrm{i}^{\text {th }}$ contingency and $\operatorname{Sev}\left(E_{i}, V_{i}\right)$ : is the severity function which quantifies the impact of the $i^{\text {th }}$ contingency with variation of the bus voltage.

This modified equation (11) is used to evaluate the total low voltage risk for all probable contingencies. The probability of the stressed voltage and the severity function are multiplied together and the area under the resultant curve is evaluated. The area and the probability of contingency are multiplied to give the risk index of low voltage of a particular stressed bus.

In evaluating the risk indices, the following assumptions were made;

Assumptions:

- We invoke the assumption usually made for security assessment that a short term operating condition is given.

- The given operating condition has strong correlation with the condition in the near future so that we can predict the expectation of the future condition very well and that the variation of future condition is small and linear approximations are valid.

- The variation of the future condition away from its expectation, except for the contingences, is due to small parametric deviations.

- The steady state model of the power system is assumed and our interest is in the post contingency performance.

- The occurrences of contingencies are independent of each other and they are also independent of other system parametric deviation and the operating condition.

- The occurrence of contingency follows Poisson distribution.

- Parametric deviation follows a Multi - Variant Normal (MVN) distribution around their expected values, and the distribution of load interruption voltages is normal.

\section{MATERIALS}

MATLAB software [14] was the tool used in achieving the solution of the load flow problem of the proposed model. The simulation model of Nigerian 330kV 41-bus network was used to demonstrate the proposed model. Figure 2 shows the single line diagram of the Nigerian $330 \mathrm{kV}$ 41-bus network while the network parameters: generator data, load data, and line data are shown in the appendix. 


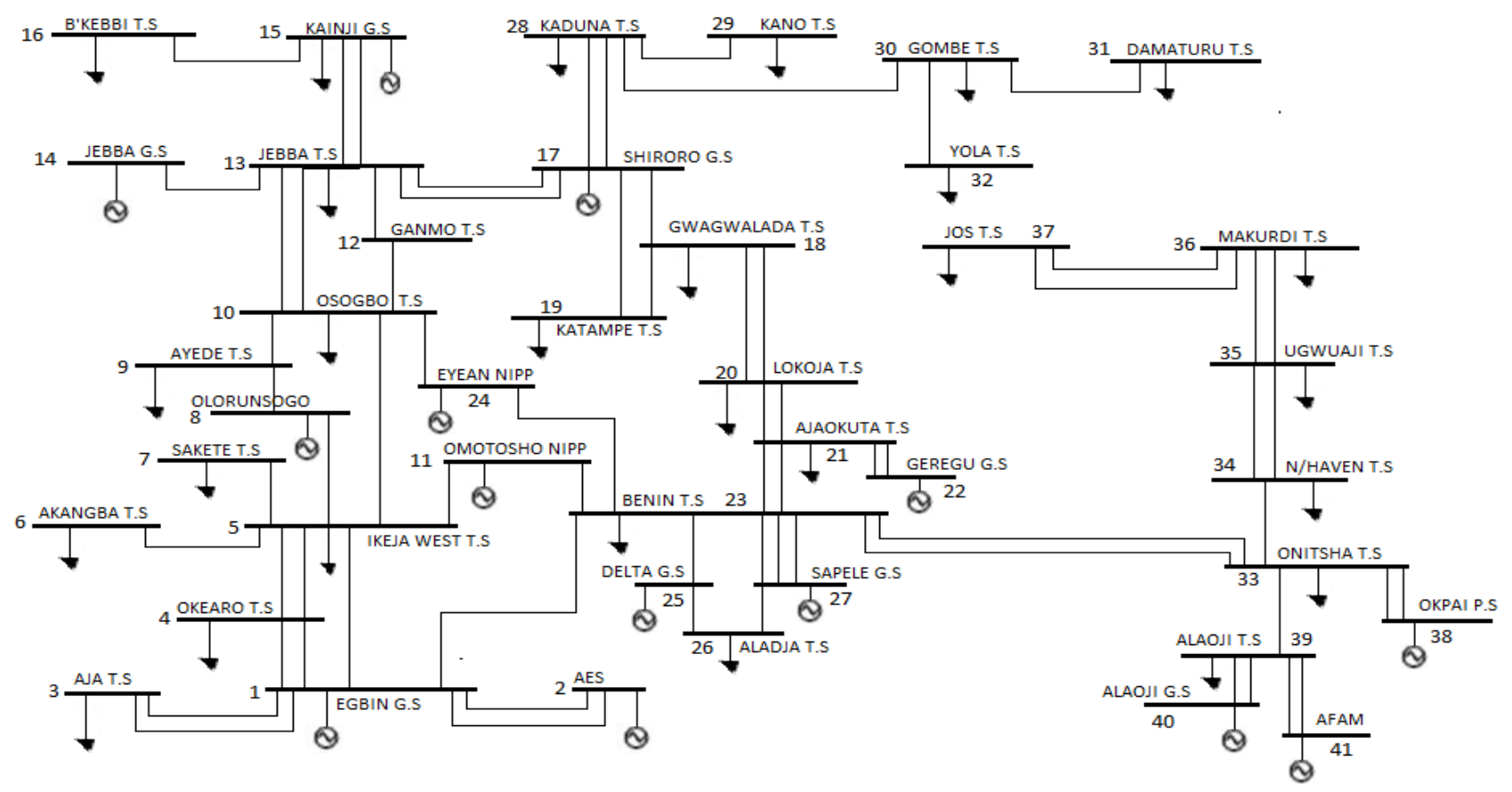

Figure 2: Single line diagram of the Nigerian 330kV 41-bus Transmission grid [15].

\section{IMPLEMENTATION}

Three contingencies were randomly simulated, contingency one on line 23-33, contingency two on line 1-5, and contingency three on line 30-31. The simulations of contingencies were carried-out assuming different yearly rates of occurrence. The assumed yearly rates of occurrence are 8, 12, 15, 20, and 25.

\section{RESULTS}

The results of voltage magnitude and risk indices obtained at various yearly rate of occurrence after simulating the contingencies are shown in Table 1, Table 2 , and Table 3 respectively.

\section{RESULT DISCUSSION}

The results indicate that as the rate of occurrence increases, the risk indices increase. It shows that contingencies with high rate of occurrence pose more risk to the system than those that rarely occur. In comparison with Nigerian power system where contingencies are frequent and no longer rare, it implies that Nigerian power system is operating under highly risky conditions.

Therefore, to operate Nigerian power system under healthy conditions, that is when setting operating boundaries to delineate between acceptable and unacceptable operating regions, the occurrence rate should be considered. The results equally show that, contingencies with high rate of occurrence with little impact possess higher or equivalent risk to contingencies with great impact, which rarely occur. Therefore, system operator, technician, and engineer should quickly identify, investigate, and proffer solution to them in order to alleviate their effects on the network. In addition, it helps in deciding on whether to leave system facilities redundant due to the most sever contingency or fully utilize the facilities in power delivery.

Table 1: Voltage magnitude and risk indices of contingency one on line 23-33

\begin{tabular}{ccccccc}
\hline \multirow{2}{*}{ Bus No } & Voltage $(\mathrm{pu})$ & \multicolumn{5}{c}{ Risk indices at various yearly rate of occurrence } \\
\cline { 3 - 6 } & & 8 & 12 & 15 & 20 & 25 \\
\hline 16 & 0.777 & 0.0016 & 0.0024 & 0.0031 & 0.0041 & 0.0051 \\
28 & 0.933 & 0.0005 & 0.0007 & 0.0009 & 0.0012 & 0.0015 \\
29 & 0.889 & 0.0008 & 0.0012 & 0.0015 & 0.0020 & 0.0025 \\
30 & 0.933 & 0.0005 & 0.0007 & 0.0009 & 0.0012 & 0.0015 \\
31 & 0.899 & 0.0007 & 0.0011 & 0.0014 & 0.0018 & 0.0023 \\
\hline & Total & 0.0041 & 0.0061 & 0.0078 & 0.0103 & 0.0129 \\
\hline
\end{tabular}


Table 2: Voltage magnitude and risk indices of contingency two on line 1-5

\begin{tabular}{|c|c|c|c|c|c|c|}
\hline \multirow{2}{*}{ Bus No } & \multirow{2}{*}{ Voltage (pu) } & \multicolumn{5}{|c|}{ Risk indices at various yearly rate of occurrence } \\
\hline & & 8 & 12 & 15 & 20 & 25 \\
\hline 16 & 0.790 & 0.0008 & 0.0012 & 0.0015 & 0.0019 & 0.0024 \\
\hline 29 & 0.946 & 0.0002 & 0.0003 & 0.0004 & 0.0005 & 0.0006 \\
\hline 31 & 0.940 & 0.0002 & 0.0003 & 0.0004 & 0.0006 & 0.0007 \\
\hline & & 0.0012 & 0.0018 & 0.0023 & 0.0030 & 0.0037 \\
\hline
\end{tabular}

Table 3: Voltage magnitude and risk indices of contingency three on line 30-31

\begin{tabular}{|c|c|c|c|c|c|c|}
\hline \multirow{2}{*}{ Bus No } & \multirow{2}{*}{ Voltage (pu) } & \multicolumn{5}{|c|}{ Risk indices at various yearly rate of occurrence } \\
\hline & & 8 & 12 & 15 & 20 & 25 \\
\hline 16 & 0.798 & 0.0018 & 0.0028 & 0.0034 & 0.0046 & 0.0057 \\
\hline 28 & 0.923 & 0.0007 & 0.0010 & 0.0013 & 0.0017 & 0.0022 \\
\hline 29 & 0.902 & 0.0009 & 0.0013 & 0.0017 & 0.0022 & 0.0028 \\
\hline 30 & 0.923 & 0.0007 & 0.0010 & 0.0013 & 0.0017 & 0.0022 \\
\hline 31 & 0.923 & 0.0007 & 0.0010 & 0.0013 & 0.0017 & 0.0022 \\
\hline \multicolumn{2}{|c|}{ Total } & 0.0048 & 0.0071 & 0.0090 & 0.0119 & 0.0151 \\
\hline
\end{tabular}

\section{CONCLUSION}

Risk is decomposable and can be decomposed by perverting the conditions that make the network risky. Such conditions include contingencies with high rate of occurrence with little impact as well as contingencies that rarely occur with great impact. Hence, to operate the power system in healthy conditions in risk based security assessment, these risky scenarios have to be prevented. Therefore, adopting the risk based security assessment methods in Nigeria will help to alleviate the epileptic nature of the power system and improve power delivery to consumers because this method will help system operators, engineers, and technicians to quickly identify, investigate and proffer solution to risky scenarios.

\section{REFERENCES}

[1] Elgerd, 0. I. Electric Energy System Theory, New Delhi, Tata McGrew-Hill, 1983.

[2] Transmission Company of Nigeria, National Control Centre Oshogbo Daily Operational Report, $31^{\text {st }}$ May 2017.

[3] Izuegbunam, F. I., Ubah, C. B. and Akwukwaegbu, I. O. "Dynamic Security Assessment of 330KV Nigeria Power System", Academic Research International, Vol. 3, Number 1, pp. 456-466, 2012.

[4] Nnonyelu, C. J. Anyaka, B. O. and Madueme, T. C. "Power System Contingency Analysis: A Study of Nigeria's 330KV Transmission Grid", Proceedings of the $4^{\text {th }}$ Electrical Engineering National Conference, University of Nigeria, Nsukka, Nigeria, July, 21-23, pp. 250-258, 2013.

[5] Asibeluo, U. N. and Madueme, T. C. "Power System Security Improvement by a Linear Approximation
Method", International Journal of Engineering Trends and Technology, Vol. 27, Number 2, pp. 7478, 2015.

[6] McCalley, J., Asgarpoor, S., Bertling, L., Billinton, R. Chao, H., Chen, J., Endrenyi, J., Fletcher, R., Ford, R., Grigg, C., Hamoud, G., Logan, D., Meliopoulos, A. P., Ni, M., Rau, N., Salvaderi, L., Schilling, M., Schlumberger, Y., Schneider, A. and Singh, C. "Probabilistic Security Assessment for Power System Operations", A Task Force Organized by the IEEE PES Reliability, Risk and Probability Applications Subcommittee, 2001.

[7] De-Martinis, U. and Battiselli, C. "Deterministic and Risk Based Approaches to Power Systems Security Assessment", International Congresses on Electrical Engineering, Catania, September, 27 29, pp. 1-8, 2009

[8] Kirschen, D. S. and Jayaweera, D. "Comparison of Risk and Deterministic Security Assessments", IET Generation, Transmission, Distribution, Vol. 1, Issue 4, pp. 527-533, 2007.

[9] Vaughan, E. J. Risk Management, New York, John Wiley and Sons, 1971.

[10] Dissanayaka, A. "Risk Based Dynamic Security Assessment", MSc Dissertation, The University of Manitoba Winnipeg, Manitoba, Canada, August 2010.

[11] Marsadek, M., Mohamed, A., and Norpiah, Z. M. "Risk Assessment of Line Overload in a Practical Power System Considering Different Types of Security Functions", Proceedings of the $9^{\text {th }}$ WSEAS International Conference on Applications of Electrical Engineering, pp. 74-79, 2010.

[12] Stott, B and Alsco, 0. "Fast Decoupled Load Flow", IEEE Transaction on Power Apparatus and Systems, Vol. PAS-93, June, pp. 859-869, 1974. 
[13] Ni, M., McCalley, J. D., Vittal, V. and Tayyib, T. "Online Risk - Based Security Assessment", IEEE Transactions on Power Systems, Vol. 18, Number 1, pp. $258-265,2003$.

[14] MATLAB Software (Version 8.2). The MathWorks, Inc., Natick, Massachusetts, United States, 2013b.

[15] Asibeluo, U. N. "Risk-Based Security Assessment of Power System", MSC Dissertation, Nnamdi Azikiwe University, Awka, Nigeria, January 2017.

\section{APPENDIX}

Table 4. Generator bus data of Nigerian 330kV 41Bus Network

\begin{tabular}{llll}
\hline Bus No. & Bus Name & P $(\mathrm{MW})$ & Q (MVar) \\
\hline 1 & Egbin & 0 & 0 \\
2 & AES & 520 & -18.578 \\
8 & Olorunsogo & 525.6 & -79.183 \\
11 & Omotosho & 305.9 & -75.119 \\
14 & Jebba G.S & 80.0 & -145.997 \\
15 & Kainji G.S & 200.0 & 145.833 \\
17 & Shiroro G.S & 108.0 & 70.513 \\
22 & Geregu G.S & 243.0 & -96.075 \\
24 & Eyean & 343.0 & -213.429 \\
25 & Delta G.S & 503.0 & -109.474 \\
27 & Sapele G.S & 153.0 & -94.814 \\
38 & Okpai G.S & 248.0 & -52.732 \\
40 & Alaoji G.S & 148.0 & 37.930 \\
41 & Afam & 508.0 & 136.981 \\
\hline
\end{tabular}

$$
\text { Source: [16] }
$$

Table 5.Load Bus Data of Nigerian 330kV 41-Bus Network

\begin{tabular}{llll}
\hline Bus No. & Bus Name & P (MW) & Q (MVar) \\
\hline 3 & Aja T.S & 120.0 & 161.5 \\
4 & Okearo T.S & 130.0 & 186.0 \\
5 & Ikeja West T.S & 698.5 & 338.1 \\
6 & Akangba T.S & 89.8 & 26.7 \\
7 & Sakete T.S & 55.0 & 15.0 \\
9 & Ayede T.S & 156.0 & 61.5 \\
10 & Osogbo T.S & 16.8 & 114.5 \\
12 & Ganmo T.S & 30.8 & 24.5 \\
13 & Jebba T.S & 117.4 & 63.5 \\
16 & B'Kebbi T.S & 276.0 & 224.5 \\
18 & Gwagwalada T.S & 26.0 & 94.5 \\
19 & Katampe T.S & 56.0 & 94.5 \\
20 & Lokoja T.S & 26.0 & 14.5 \\
21 & Ajaokuta T.S & 16.0 & 4.5 \\
23 & Benin T.S & 134.0 & 46.5 \\
26 & Aladja T.S & 14.0 & 46.5 \\
28 & Kaduna T.S & 286.0 & 114.5 \\
29 & Kano T.S & 305.0 & 49.0 \\
30 & Gombe T.S & 196.0 & 164.5 \\
\hline
\end{tabular}

\begin{tabular}{llll}
\hline Bus No. & Bus Name & P (MW) & Q (MVar) \\
\hline 31 & Damaturu T.S & 156.0 & 85.5 \\
32 & Yola T.S & 85.0 & 26.5 \\
33 & Onitsha T.S & 326.0 & 114.5 \\
34 & New Haven T.S & 154.0 & 64.5 \\
35 & Ugwuaji T.S & 86.0 & 34.5 \\
36 & Makudi T.S & 39.0 & 12.5 \\
37 & Jos T.S & 90.0 & 140.5 \\
39 & Alaoji T.S & 414.2 & 330.5 \\
\hline
\end{tabular}

Source: [16]

Table 6.Line Data of Nigerian 330KV 41Bus Network

\begin{tabular}{ccccc}
\hline From & To & $\mathrm{R}(\mathrm{pu})$ & $\mathrm{X}(\mathrm{pu})$ & $1 / 2 \mathrm{~B}(\mathrm{pu})$ \\
\hline 1 & 2 & 0.0011 & 0.0220 & 0.178 \\
1 & 2 & 0.0011 & 0.0220 & 0.178 \\
1 & 3 & 0.0005 & 0.0043 & 0.053 \\
1 & 3 & 0.0005 & 0.0043 & 0.053 \\
1 & 4 & 0.0006 & 0.0055 & 0.068 \\
1 & 4 & 0.0006 & 0.0055 & 0.068 \\
1 & 5 & 0.0006 & 0.0055 & 0.068 \\
4 & 5 & 0.0006 & 0.0055 & 0.068 \\
4 & 5 & 0.0006 & 0.0055 & 0.068 \\
5 & 6 & 0.0006 & 0.0047 & 0.070 \\
5 & 6 & 0.0006 & 0.0047 & 0.070 \\
5 & 7 & 0.0025 & 0.0213 & 0.266 \\
5 & 8 & 0.0028 & 0.0234 & 0.292 \\
5 & 10 & 0.0090 & 0.0760 & 0.949 \\
5 & 11 & 0.0028 & 0.0234 & 0.292 \\
8 & 9 & 0.0021 & 0.0182 & 0.228 \\
9 & 10 & 0.0041 & 0.0349 & 0.437 \\
10 & 12 & 0.0017 & 0.0143 & 0.178 \\
10 & 13 & 0.0056 & 0.0477 & 0.596 \\
10 & 13 & 0.0056 & 0.0477 & 0.596 \\
12 & 13 & 0.0039 & 0.0133 & 0.418 \\
13 & 14 & 0.0003 & 0.0022 & 0.033 \\
13 & 14 & 0.0003 & 0.0022 & 0.033 \\
13 & 15 & 0.0029 & 0.0246 & 0.308 \\
13 & 15 & 0.0029 & 0.0246 & 0.308 \\
15 & 16 & 0.0111 & 0.0942 & 1.177 \\
17 & 13 & 0.0087 & 0.0742 & 0.927 \\
17 & 13 & 0.0087 & 0.0742 & 0.927 \\
18 & 17 & 0.0053 & 0.0406 & 0.606 \\
19 & 17 & 0.0079 & 0.0607 & 0.902 \\
19 & 18 & 0.0026 & 0.0200 & 0.299 \\
20 & 18 & 0.0063 & 0.0486 & 0.725 \\
20 & 18 & 0.0063 & 0.0486 & 0.725 \\
20 & 21 & 0.0017 & 0.0132 & 0.197 \\
20 & 21 & 0.0017 & 0.0132 & 0.197 \\
21 & 22 & 0.0001 & 0.0005 & 0.006 \\
21 & 22 & 0.0001 & 0.0005 & 0.006 \\
21 & 23 & 0.0071 & 0.0543 & 0.807 \\
21 & 23 & 0.0071 & 0.0543 & 0.807 \\
& & & & \\
1 & & \\
1 & & \\
1 & & \\
1 & &
\end{tabular}

Vol. 37, No. 3, July, 2018 


\begin{tabular}{ccccc}
\hline From & To & $\mathrm{R}(\mathrm{pu})$ & $\mathrm{X}(\mathrm{pu})$ & $1 / 2 \mathrm{~B}(\mathrm{pu})$ \\
\hline 23 & 1 & 0.0072 & 0.0608 & 0.759 \\
23 & 24 & 0.0009 & 0.0076 & 0.095 \\
23 & 11 & 0.0018 & 0.0155 & 0.194 \\
24 & 10 & 0.0089 & 0.0762 & 0.953 \\
25 & 23 & 0.0015 & 0.0125 & 0.156 \\
25 & 26 & 0.0011 & 0.0097 & 0.122 \\
26 & 27 & 0.0023 & 0.0191 & 0.239 \\
27 & 23 & 0.0018 & 0.0139 & 0.207 \\
27 & 23 & 0.0018 & 0.0139 & 0.207 \\
27 & 23 & 0.0018 & 0.0139 & 0.207 \\
28 & 17 & 0.0034 & 0.0292 & 0.365 \\
28 & 17 & 0.0034 & 0.0292 & 0.365 \\
28 & 29 & 0.0082 & 0.0699 & 0.873 \\
28 & 30 & 0.0085 & 0.0711 & 0.889 \\
30 & 31 & 0.0064 & 0.0547 & 0.684 \\
30 & 32 & 0.0086 & 0.0729 & 0.911 \\
33 & 23 & 0.0049 & 0.0416 & 0.520 \\
\hline
\end{tabular}

\begin{tabular}{ccccc}
\hline From & To & $\mathrm{R}(\mathrm{pu})$ & $\mathrm{X}(\mathrm{pu})$ & $1 / 2 \mathrm{~B}(\mathrm{pu})$ \\
\hline 33 & 23 & 0.0049 & 0.0416 & 0.520 \\
33 & 34 & 0.0034 & 0.0292 & 0.365 \\
34 & 35 & 0.0003 & 0.0019 & 0.029 \\
34 & 35 & 0.0003 & 0.0019 & 0.029 \\
35 & 36 & 0.0017 & 0.0132 & 0.197 \\
35 & 36 & 0.0017 & 0.0132 & 0.197 \\
36 & 37 & 0.0103 & 0.0796 & 1.187 \\
36 & 37 & 0.0103 & 0.0796 & 1.187 \\
38 & 33 & 0.0022 & 0.0167 & 0.248 \\
38 & 33 & 0.0022 & 0.0167 & 0.248 \\
39 & 33 & 0.0049 & 0.0419 & 0.524 \\
40 & 39 & 0.0021 & 0.0182 & 0.228 \\
40 & 39 & 0.0021 & 0.0182 & 0.228 \\
41 & 39 & 0.0009 & 0.0069 & 0.103 \\
41 & 39 & 0.0009 & 0.0069 & 0.103 \\
\hline \multicolumn{5}{c}{ Source $[16]$}
\end{tabular}

